[4] Rau R, Schütte H. Results of radiosynoviorthesis with yttrium 90 in chronic synovitis: a long-term prospective study. I. Total results and effect of local factors. Z Rheumatol. 1983; 42: 265-70.

Disclosure of Interests: None declared

DOI: 10.1136/annrheumdis-2019-eular.2843

\section{THU0578 COMMON VARIABLE INMUNODEFICIENCY IN PATIENTS WITH SARCOIDOSIS}

Isabel Madroñal García, Clara Aguilera Cros, Maria Dolores Arcila Duran, Lara Mendez, Marina Gomez Vargas, Alberto Ruiz Roman, Noemi Patricia Garrido Puñal, Ricardo Juan Gil Velez, Jose Antonio Rodriguez Portal, Esteban Rubio Romero. Hospital Universitario Virgen del Rocío, Reumatologia, Sevilla, Spain

Background: Common variable immunodeficiency (CVID) is a primary immunodeficiency characterized by hypogammaglobulinemia and a deficient production of specific antibodies. Almost $30 \%$ of patients with CVID develop an autoinmmune and granulomatous disease, similar to clinical and histological sarcoidosis (S), it affects the lung fundamentally. This can lead to a misdiagnosis of $S$ in a patient with CVID, this leads to inadequate treatment and increases the morbidity and mortality of the disease.

Objectives: Describe the clinical and radiological characteristics of a cohort of patients diagnosed with $S$ with predominant pulmonary involvent. Make a study of immunoglobulin (IG) levels to see the frequency of CVID in these patients.

Methods: Retrospective descriptive study of patients treated in our Hospital (2008-2018), with diagnosis of S. The data was obtained by reviewing medical records. The delay in the diagnosis of $S$ was defined as the difference in months between the initial diagnostic suspicion and the final diagnosis of $\mathrm{S}$.

In patients with low levels IG, we have done and expanded ID study.

Results: 55 patients (31 women) were included, with a mean age of 52 \pm 12 years. The initial diagnosis was: $85 \% \mathrm{~S}, 10 \%$ lymphoma and $4 \%$ tuberculosis. The median of months from the start of the clinic to the diagnosis of $\mathrm{S}$ was 5.5 months.

Regarding the clinic, $21 \%$ patients present fever at the beginning of the disease, and $65 \%$ extrathoracic localization (cutaneous was the most frequent in $27 \%$, and renal was the least frequent $5 \%$ ). Simple $x$-ray and high resolution tomography of chest were done in all patients. Pulmonary stage 2 was the most frequent $(51 \%)$, followed by stage $3(16 \%)$, stage $0(14 \%)$ and stage $4(9 \%)$.

In $90 \%$ of the patients, histological confirmation was obtained by transbronchial $(47 \%)$, cutaneous $(11 \%)$ or lymph node biopsy $(29 \%)$.

Igs were normal in $87 \%$ of patients, only 4 patients had low IG levels ( Ig $G$ in 3 patients and $\lg M$ in 1). An extended ID study was performed in these 4 patients, being diagnosed with CVID 3 patients.

Results of the 4 patients and the differential characteristics between CVID and $S$ in table 1.

\begin{tabular}{|c|c|c|c|c|c|c|}
\hline $\begin{array}{l}\text { Differential } \\
\text { diagnosis }\end{array}$ & CVID & Sarcoidosis & Patient 1 & Patient 2 & Patient 3 & Patient 4 \\
\hline $\begin{array}{l}\text { Recurrent } \\
\text { infections }\end{array}$ & +++ & $+/-$ & Yes & Yes & Yes & Yes \\
\hline Autoimmunity & +++ & + & Yes & Yes & No & No \\
\hline Splenomegaly & +++ & $+/-$ & Yes & Yes & Yes & Yes \\
\hline Hepatomegaly & +++ & $+/-$ & Yes & Yes & Yes & Yes \\
\hline Low levels IG & +++ & $+/-$ & Yes & Yes & Yes & $\begin{array}{c}\text { Low levels } \\
\text { IgM }\end{array}$ \\
\hline Clinic & & & Pulmonary & Pulmonary & Pulmonary & Pulmonary \\
\hline $\begin{array}{l}\text { Radiological } \\
\text { stage }\end{array}$ & & & Stage 2 & Stage 2 & Stage 2 & Stage 2 \\
\hline $\begin{array}{l}\text { Histological } \\
\text { granuloma }\end{array}$ & +++ & +++ & Yes & Yes & Yes & Yes \\
\hline $\begin{array}{l}\text { Increase of } \\
\text { CD4/CD8 in } \\
\text { BAL }\end{array}$ & + & +++ & Low levels & Low levels & Low levels & Not done \\
\hline Treatment & & & Corticoids & Corticoids & Corticoids & Corticoids \\
\hline
\end{tabular}

Conclusion: Although their clinical presentation and histological appearance may be identical, the management of these two conditions is very different. The difficulties in the differential diagnosis between $S$ and CVID, shows the importance of a history of screening for recurrent infections and the measurement of IG levels before the diagnosis of possible $S$.

Disclosure of Interests: None declared

DOI: 10.1136/annrheumdis-2019-eular.6339

\section{THU0579}

CHEMOKINE AND CYTOKINE TEARS PROFILE OF PATIENTS WITH IGG4-RELATED DISEASE

Eduardo Martin-Nares, Luis Llorente, Isela Chan-Campos, Diego HernándezRamírez, Guadalupe Lima, Vanessa Saavedra-González, Gabriela HernandezMolina. Instituto Nacional de Ciencias Médicas y Nutrición Salvador Zubirán, Immunology and Rheumatology, Mexico City, Mexico

Background: The lacrimal gland is frequently involved in both lgG4 related disease (IgG4-RD) and Sjögren's syndrome (SS) and presents with swelling and/or dry eye symptoms. Although a distinct chemokine and cytokine tear profile might distinguish SS from idiopathic dry eye, as of today no study has assessed this issue in IgG4-RD.

Objectives: To evaluate and compare a set of chemokine/cytokine in the tears of patients with IgG4-RD and primary SS.

Methods: We included 11 patients with IgG4-RD according to the Com prehensive Diagnostic Criteria for IgG4-RD and 17 with primary SS according the AECG criteria, who attended a tertiary referral center in Mexico City. Schirmer-I test were performed using two standardized sterile tear strips, and then immediately frozen at $-86^{\circ} \mathrm{C}$ until assayed. Once defrosted, the tears were extracted from the strips using a buffer containing $0.5 \mathrm{M} \mathrm{NaCl}$ and $0.5 \%$ Tween-20. Then, the amount $(\mathrm{pg} / \mathrm{mL})$ of the following selected chemokines and cytokines were measured by Luminometry: CCL11, G-CSF, IFN- $\gamma$, IL-12p40, IL-12p70, IL-13, IL-17A, IL-1 $\alpha$, IL$1 \beta$, IL-4, IL-7, CXCL10, CCL2, CCL3, CCL4 and TNF- $\alpha$.

Results: Patients with IgG4-RD were younger $(51.3 \pm 14.7$ vs. $55.7 \pm 10.6)$ and more frequently men $(45.5 \%$ vs. $5.9 \%)$ than SS patients. Regarding the IgG4-RD group, $7(63.6 \%)$ had lacrimal gland involvement, $5(45.5 \%)$ dry eye symptoms and $6(54.5 \%)$ positive Schirmer-I test. We observed multi-organic involvement in 9 patients $(81.8 \%)$, median number of involved organs of $5,9(81.8 \%)$ patients had active disease, median IgG4-RD responder index of 6 points, $8(72.7 \%)$ patients had high IgG4 serum levels, and $9(81.8 \%)$ biopsy proven diagnosis. We found higher levels of IL-7 and CCL2, and a trend for G-CSF in the IgG4-RD group. Conversely, primary SS patients had higher levels of IL-12p40, IL-1 $\alpha$, IL$1 \beta$, CCL3 and CCL4. At the logistic regression analysis, the variables that remained associated with IgG4-RD were IL-7 (OR $1.4395 \% \mathrm{Cl}$ 1.06-1.93, $\mathrm{p}=0.01$ ) and IL12p40 (OR 0.92, 95\% Cl 0.84-0.99, $\mathrm{p}=0.01$ ).

In a sensitivity analysis, including only 7 IgG4-RD patients with dacryoadenitis, we also observed higher levels of IL-7 and G-CSF in the IgG4$\mathrm{RD}$ group vs primary SS.

Conclusion: The chemokine and cytokine profile of tears of patients with IgG4-RD is characterized by a mixed immune response (Th1/Th2/Th17) compare with a predominantly Th1 response in primary SS. Our results also suggest a possible role of IL-7 in the pathogenesis of IgG4-RD.

\section{REFERENCES}

[1] Hernández-Ruiz M, Zlotnik A, Llorente L, Hernandez-Molina G. Markedly high salivary and lacrimal CXCL17 levels in primary Sjögren's syndrome. Joint Bone Spine. 2018 May;85(3):379-380.

Table 1:

\begin{tabular}{lccc}
\hline $\begin{array}{l}\text { Chemokine/cytokine pg/mL, median } \\
\text { (range) }\end{array}$ & IgG4-RD $\mathrm{n}=\mathbf{1 1}$ & $\mathrm{pSS} \mathrm{n}=\mathbf{1 7}$ & $\boldsymbol{p}$ \\
\hline CCL11 & $11.9(3.7-34.4)$ & $15.4(3.7-33.0)$ & 0.06 \\
G-CSF & $118.7(14.5-325.9)$ & $88.5(14.5-226.5)$ & 0.08 \\
IFN- - & $1.3(0.3-2.1)$ & $1.7(0.01-7.2)$ & 0.19 \\
IL-12p40 & $8.7(1.3-35.5)$ & $24.1(1.3-69.3)$ & 0.02 \\
IL-12p70 & $0.5(0.09-3.1)$ & $1.6(0.09-28.1)$ & 0.05 \\
IL-13 & $19.2(4.6-84.9)$ & $18.1(2.4-75.0)$ & 0.30 \\
IL-17A & $0.9(0.2-1.7)$ & $0.9(0.08-4.9)$ & 0.89 \\
IL-1 $\alpha$ & $25.8(10.5-166.8)$ & $54.3(21.6-119.1)$ & 0.003 \\
IL-1 $\beta$ & $0.1(0.1-1.5)$ & $1.5(0.1-7.2)$ & 0.001 \\
IL-4 & $11.0(1.8-17.6)$ & $8.2(1.8-19.8)$ & 0.45 \\
IL-7 & $13.8(6.6-65.1)$ & $6.4(1.27-15.0)$ & 0.001 \\
CXCL10 & $5399.5(296.9-$ & $5368.1(1205-$ & 0.51 \\
& $11394)$ & $11553.6)$ & \\
CCL2 & $11.4(1.1-104.4)$ & $1.1(1.1-166.3)$ & 0.03 \\
CCL3 & $2.4(0.3-4.0)$ & $3.4(1.1-40.7)$ & 0.01 \\
CCL4 & $1.2(1.2-27.6)$ & $11.1(1.2-164.3)$ & 0.02 \\
TNF- $\alpha$ & $0.8(0.1-5.4)$ & $2.03(0.1-7.6)$ & 0.06 \\
\hline
\end{tabular}

Disclosure of Interests: None declared DOI: 10.1136/annrheumdis-2019-eular.4183 